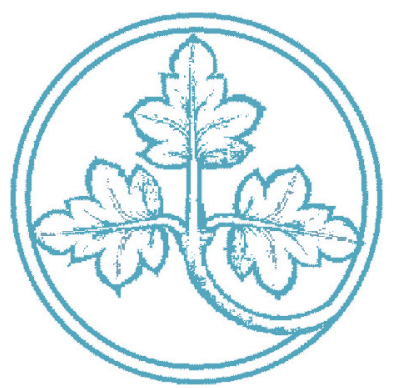

A Comparison between Political Claims Analysis and Discourse Network Analysis: The Case of Software Patents in the European Union

Philip Leifeld

Sebastian Haunss

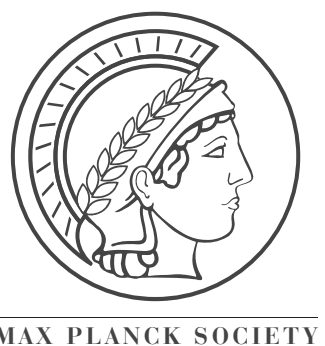




\title{
A Comparison between Political Claims Analysis and Discourse Network Analysis: The Case of Software Patents in the European Union
}

\author{
Philip Leifeld / Sebastian Haunss
}

May 2010 


\title{
A Comparison between Political Claims Analysis and Discourse Network Analysis: The Case of Software Patents in the European Union*
}

\author{
Philip Leifeld ${ }^{\dagger}$ and Sebastian Haunss
}

\begin{abstract}
The study of policy discourse comprises actor-centered and content-oriented approaches. We attempt to close the gap between the two kinds of approaches by introducing a new methodology for the analysis of political discourse called Discourse Network Analysis. It is based on social network analysis and qualitative content analysis and takes an entirely relational perspective. Political discourse can be analyzed in a dynamic way, and the approach makes previously unobservable cleavage lines and alignments measurable at the actor level, at the level of the contents of a discourse, and a combined layer. We compare discourse network analysis with political claims analysis, a competing method, and apply both methods to the European-level discourse on software patents. Our results demonstrate how an anti-software-patent coalition was mobilized and how it gained control over important frames, while the well-organized pro-software-patent discourse coalition was not able to gain sovereignty over the discourse.
\end{abstract}

Keywords: Software Patents, Intellectual Property Rights, Discourse Network Analysis, Social Network Analysis, Political Discourse, Policy Networks, Public Policy Analysis, Social Movements, Political Claims Analysis

\section{Introduction}

Between 1997 and 2005, the question whether software patents should be allowed in Europe became one of the most contentious issues in which the European Parliament and the other European institutions have ever been involved. At the end of the political process, the European Parliament rejected the directive "on the patentability of computer-implemented inventions", which had been drafted and supported by the European Commission, the Council, and well-organized industrial interests, with an overwhelming majority. From the dominant resource-centered perspective of the interest-group literature, a resource-poor coalition of the "weak" was able to prevail over a resourceful coalition of "strong" actors (Beyers 2004; Bouwen 2004; Kohler-Koch 1997). How could this unusual case happen?

We posit that an explanation must be sought in the realm of political discourse and its dynamics. To understand political mobilizations, conflicts, and decisions, it is necessary to account

\footnotetext{
* The authors would like to thank Christoph Engel, Nina Horstmann, Volker Schneider and Jeremy Rayner for helpful comments and the Max Planck International Research Network on Aging for financial support.

$\dagger$ Max Planck Institute for Research on Collective Goods, Bonn.

$\$$ Department of Politics and Management, University of Konstanz.
} 
for the various verbal and symbolic interventions that precede and accompany them. The insight that discourse matters in politics predates what has sometimes been called the "linguistic turn" in the social sciences or the "argumentative turn" in political science. These more recent developments have certainly spurred research in this area; today there exists a substantial body of research about political discourses (for an overview, see Janning et al. 2009). But within the multitude of theoretical and empirical contributions, there is still a gap between content-oriented and actor-centered approaches to political discourse. This article will shed light on this missing link and introduce a novel methodology for analyzing political discourses empirically as well as theoretically. The approach called discourse network analysis is compared with a competing method, political claims analysis, and both methods are applied to the European-level discourse on software patents. The results indicate that discourse network analysis outperforms political claims analysis in many respects.

Even though it would be beyond the scope of this paper to offer a full-fledged explanation of the political outcome in the software patents case, we strive to demonstrate empirically with our methods that the proponents of software patents did not manage to acquire hegemony in the political discourse.

The structure of the article is as follows: the second section reviews existing approaches to political discourse with an emphasis on political claims analysis and discourse network analysis. Section 3 applies political claims analysis to the European-level discourse on software patents. Section 4 introduces discourse network analysis and subsequently applies it to the same data. The section ends with a comparison of both approaches. The article concludes with a summary of relative merits and drawbacks of discourse network analysis.

\section{State of the art}

The research on elite political discourse can be roughly divided into content-oriented and actor-centered approaches. Typical questions of a content-oriented approach are: which competing frames exist, how are they connected to political goals and power, and which concepts in the discourse are related to each other? Critical discourse analysis (Wodak \& Meyer 2009), semantic network analysis (Brandes \& Corman 2003; Popping 2003) and analyses of legitimacy discourses (Hurrelmann et al. 2009; Hurrelmann et al. 2007) are typical examples of research with this perspective.

In the latter example, arguments of legitimation and de-legitimation are identified on the basis of a systematic analysis of newspaper articles to answer the question whether de-parliamentization and transnationalization erode the sources of legitimacy of national political systems. In these studies, legitimation patterns are occasionally linked to the actors who use them. However, the focus is clearly on the revelation of patterns in the contents of the political discourse while actors play a subordinate role. 
In contrast, the actor-centered approach to political discourse deals with configurations of policy subsystems along the lines of the actors' preferences or ideas. This approach thus concentrates on changes in the mutual attachment of actors to explain policy change. Examples of actor-centered approaches to political discourse are the Advocacy Coalition Framework (Sabatier \& Weible 2007), Punctuated Equilibrium Theory (Baumgartner \& Jones 1991), epistemic communities (Haas 1992), discourse coalitions (Hajer 1995), and policy paradigms (Hall 1993).

The Advocacy Coalition Framework provides a typical example: actors are grouped into approximately two coalitions. Policy core beliefs are the "glue that binds coalitions together" (Sabatier \& Weible 2007), i.e., beliefs are more similar within a coalition than between coalitions. There are constant attempts of the coalitions to convince each other of their policy belief systems. This interaction constitutes the political discourse. If external events lead to learning processes and changes in the affiliation of pivotal actors to coalitions, policy change becomes likely. The focus of this approach is on the learning behavior of actors, while the different concepts within the discourse play a subordinate role.

Both approaches, content-oriented and actor-centered, treat the connection between actors and concepts as secondary factors. They do not analyze the co-evolution of actor configurations and ideas in a systematic way. As Steensland observes, "few existing studies link frames with the actors who sponsor them, thus presenting an oddly disembodied picture of framing processes" (Steensland 2008, p. 1031). In addition, discourses, let alone the co-evolution of actors and ideas, are rarely systematically analyzed in longitudinal way: "This dimension of policymaking has proven especially difficult to model. Like subatomic particles, ideas do not leave much of a trail when they shift. [...] We need more studies of the evolution of policy over time, a subject that has often been neglected relative to static, one-shot comparisons of policy across nations" (Hall 1993, p. 290ff.).

One of the few exceptions is political claims analysis (PCA) (Koopmans \& Statham 1999), which tries to establish the missing link between actors and contents in a discourse by employing a distinct set of methods, particularly a classification of actors as well as frames on a one-dimensional pro/contra scale and time series graphs of discourse activity. The substantial number of empirical applications of this hybrid approach includes political discourses on ethnic relations, citizenship and immigration (Dolezal et al. 2010; Giugni \& Passy 2004; Koopmans \& Statham 2001), European integration (Statham \& Gray 2005), on intellectual property rights (Haunss \& Kohlmorgen 2009), and the Danish Muhammad caricatures controversy (Lindekilde 2008).

Political claims analysis was introduced by Koopmans and Statham (1999) to overcome the weaknesses of protest event data analysis by collecting data not just on the actors and forms of action, but also on the interpretations by actors involved in political conflicts. The method thereby combines protest event analysis and discourse analysis. It expands the scope of the 
former beyond protesters and protests by conceiving claims as demands, criticisms, demonstrations, decisions, and other kinds of political interventions conducted by actors. The goal of PCA is to "trace the shifting alliances and oppositions between actors that evolve in the dynamic process of a political conflict" (Koopmans \& Statham 1999, p. 6). Data on political claims is usually collected from newspaper articles. The unit of analysis is the claims (not the protest). Each time an actor makes a claim, this action or statement is manually coded along with various other variables containing information about the actor, the context, addressees, opponents, aims, and frames, among others. ${ }^{1}$

Drawing on PCA data, authors have been able to construct time lines of media attention towards movements and policies (Beyeler \& Kriesi 2005), to identify differential participation and differences in the construction of collective identities of claimants across polities (Koopmans \& Statham 2001), and, more generally, to analyze the salience of issues and patterns of participation and mobilization.

In addition, since issue stances are also recorded, PCA allows for an analysis of actor positions on each issue on a one-dimensional scale ranging from complete endorsement to complete rejection.

In sum, PCA so far has been used

- to identify the "multi-organizational field" of relevant actors, subdivided into several categories like "media", "churches" or "federal legislative",

- to analyze the distribution of claims between these organizational types and compare them within or between polities,

- to map frames and actors on a one-dimensional scale, depending on how many claims actors make in favor of the contentious issue or against it,

- to identify brokers who are located in the middle of this pro/contra scale,

- to assess the degree of polarization between frames and/or claimants on the one-dimensional scale,

- to count the relative frequencies of certain frames among all claims in order to measure the relative importance of certain subtopics,

- and to generate time series graphs of statement frequencies that can be used to visualize the intensity of conflicts over time (e.g., Haunss \& Kohlmorgen 2009).

Political claims analysis thus provides a reasonable methodology to examine both actors and their frames using a single dataset, and to analyze the connections between these two classes. However, with the exception of a network analysis of addressees and opponents in the European Union enlargement debate (Adam 2008) from the Europub dataset (Koopmans 2004), the relational information contained in PCA data has not been systematically explored.

1 A frame is an "interpretive [schema] that simplifies and condenses the 'world out there' by selectively punctuating and encoding objects, situations, events, experiences, and sequences of actions within one's present or past environment" (Snow \& Benford 1992, p. 137). In the simplest form, frames are the interpretations that underpin an actor's argumentation. 
We therefore propose a novel approach to the study of political discourse which adopts an entirely relational perspective: Discourse Network Analysis (DNA) (Janning et al. 2009; Leifeld 2009; Leifeld 2010b). The approach combines qualitative content analysis and quantitative social network analysis in order to conceptualize and measure the co-evolution of actors and concepts in a dynamic way.

Discourse network analysis is closely related to and can be integrated with the policy network approach (Adam \& Kriesi 2007). Policy network analysis is actually a methodological toolbox (Kenis \& V. Schneider 1991) and can be combined with many theories (Lang \& Leifeld 2009). In this broad definition of policy network analysis, discourse networks are merely one relational type beside other relations such as resource exchange between actors or common membership in committees. They can be conceived of as an extension of policy network analysis to discursive structures. This, however, presupposes an actor-centered perspective. Discourse network analysis is in fact broader in scope because the relations between concepts in the discourse are also part of the relational model.

Table 1: Comparison of Discourse-Analytical Perspectives

\begin{tabular}{|l|c|c|c|c|}
\hline \multicolumn{1}{|c|}{ Approach } & $\begin{array}{c}\text { Actor- } \\
\text { centered }\end{array}$ & $\begin{array}{c}\text { Content- } \\
\text { oriented }\end{array}$ & $\begin{array}{c}\text { Analysis } \\
\text { of deep } \\
\text { structures }\end{array}$ & $\begin{array}{c}\text { Formaliza- } \\
\text { tion }\end{array}$ \\
\hline Advocacy Coalition Framework & $\bullet$ & $\circ$ & $\circ$ & $\circ$ \\
\hline Punctuated Equilibrium Theory & $\bullet$ & $\circ$ & $\circ$ & $\circ$ \\
\hline Discourse Coalitions & $\bullet$ & $\circ$ & $\circ$ & $\circ$ \\
\hline Policy Paradigms & $\bullet$ & $\circ$ & $\circ$ & $\circ$ \\
\hline Epistemic Communities & $\bullet$ & $\circ$ & $\circ$ & $\circ$ \\
\hline Critical Discourse Analysis & $\circ$ & $\bullet$ & $\bullet$ & $\circ$ \\
\hline Semantic Network Analysis & $\circ$ & $\bullet$ & $\circ$ & $\bullet$ \\
\hline Legitimation Discourses & $\circ$ & $\bullet$ & $\bullet$ & $\circ$ \\
\hline Political Claims Analysis & $\bullet$ & $\bullet$ & $\circ$ & $\bullet$ \\
\hline Discourse Network Analysis & $\bullet$ & $\bullet$ & $\bullet$ & $\bullet$ \\
\hline
\end{tabular}

In spite of its formalization, discourse network analysis is in the tradition of critical discourse analysis and related approaches that try to disentangle the complexities of an empirical discourse and to unravel deep structures of power and identity (cf. Wodak \& Meyer 2009) Despite their effort, we argue that existing hermeneutic approaches fail to make political discourses observable in a systematic way, particularly over time. Discourse network analysis can do both: extract deep structures from a complex discourse, and make them available to formal analytic procedures. This still presupposes manual effort and inductive multi-pass cod- 
ing by the researcher, but the approach can generate insights that are hidden to other formal coding procedures like political claims analysis or automated content analysis procedures used in semantic network analysis (e.g., Carley et al. 2009). In particular, the network visualizations display the cleavage lines present in the data as well as the frames or actor coalitions in terms of discursive similarity. This goes beyond a mere positioning approach of other formal methods of discourse analysis.

Table 1 summarizes the approaches introduced in this section. The next section will analyze the European-level political discourse on software patents using political claims analysis. The chapter is based on previous work by one of the authors (Haunss \& Kohlmorgen 2009). The added value of discourse network analysis to the analysis of the same data is presented thereafter.

\section{A political claims analysis of the European conflict about software patents}

As outlined in the introduction, the software patents conflict between 1997 and 2005 has been one of the most contentious issues in European Union politics. At the beginning of the discourse in June 1997, when the European Commission published its Green Paper with the title "Promoting innovation through patents" (COM 1997), nobody would have foreseen the contentious trajectory of this conflict. In contrast, it was generally assumed that this arcane issue would be resolved by the specialists and experts of the patent community with minimal interference. In retrospect, the software patents conflict in Europe was clearly an example of increasingly politicized disputes about intellectual property rights worldwide (Haunss \& Shadlen 2009). The issue soon started to attract the attention of many small software programmers and the free and open source community at large. The internet consultation launched by the commission received 1450 responses within two months, $91 \%$ of the responses rejecting the proposed patentability of software. Thousands of individuals, organizations, and firms signed the "EuroLinux Petition" calling for a prohibition of software patents in Europe, and in February 1999, FFII, the Federation for a Free Information Infrastructure, was founded to mobilize against the proposed directive. They stood against resource- and powerful European business associations ranging from the general European industry association UNICE (now Business Europe) to technology associations like the Business Software Association (BSA) and the European Information, Communications and Consumer Electronics Industry Technology Association (EICTA).

After the Commission had ignored all the critical submissions in its 2002 proposal for a directive "on the patentability of computer-implemented inventions", a turbulent decision-making process followed. In the first reading, the European Parliament followed in its majority the software patent opponents' arguments and de facto reversed the directive's intentions with a series of amendments, which the Commission and the Council almost completely removed in 
the so called "common position" in 2005. In the second reading in the EP, the directive was finally rejected with a huge majority of 648 to 14 votes.

During this conflict, an increasing level of public attention was paid to the issue. Whereas software patents were a topic for a very specialized audience of patent professionals in 1997, eight years later the issue was present in the politics, economy and technology pages of regular daily newspapers. 124 newspaper articles from four key countries (Germany, UK, France and Poland) containing 277 claims were the basis for a political claims analysis of the conflict whose results will be summarized below (for more detailed results see Haunss \& Kohlmorgen 2009).

Claims-making in the software patents conflict occurred in four waves following the institutional decision-making process. A relatively low-profile press coverage accompanied the consultation phase and the publication of the proposal for the directive. More intense media attention followed the parliament's first and second reading. In line with these institutionally structured media attention cycles, the group of actors whose claims appear most often in the press are the Members of the European Parliament (MEPs). They account for $18.8 \%$ of the claims, followed by civil society organizations, small and medium-sized enterprises (SMEs), large corporations, and business associations, each responsible for between 12 and $10 \%$ of the claims.

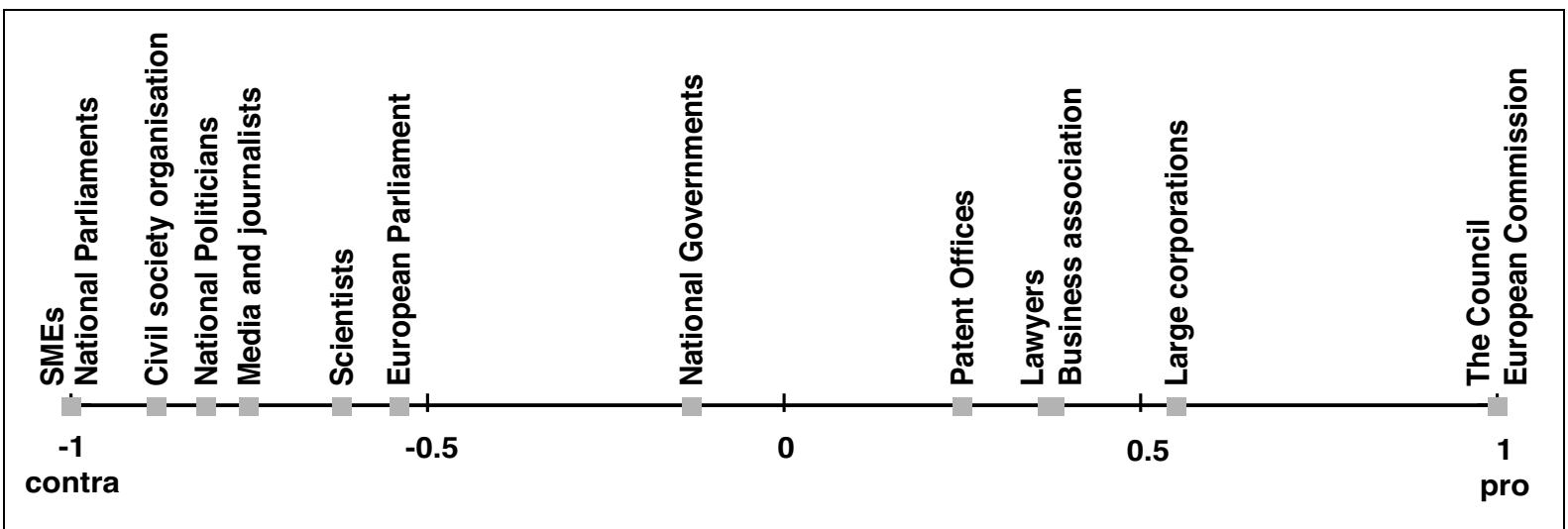

Figure 1: Mean actor positions in the software patents conflict

Note: Positions in this chart represent the mean position of actors of the respective type. Scientists, for example, were in one instance reported to support the directive, nine times reported to be against the directive, and in three instances their position was neutral or ambivalent, resulting in an overall score of $((1 \cdot 1)+(9 \cdot(-1))) / 13=-0.62$.

By considering issue stances, it is possible to construct a scale representing the average position of the actor groups involved in the conflict (figure 1). As the figure shows, one large cluster of opponents scored between -1 and -0.5 on the positional scale, together representing a little over half $(56 \%)$ of the actors mentioned in the press. At the other end of the spectrum, the Council, the Commission, lawyers, business associations, and a number of large individual firms supported the directive, but even the large firms were not unanimously in favor of it. Only the Council and the Commission unanimously supported the directive. On the other side 
of the spectrum, SMEs and national parliamentarians and parliaments are the only actors from which only frames rejecting software patents were reported. While lawyers, business associations and large corporations largely supported the directive, the positional scale nevertheless illustrates that these groups of actors were to some degree split in the conflict. The same goes for the European Parliament whose members were more often quoted in opposition than in support of the directive.

A look at the positional distribution of the frames reveals the main interpretive schemata employed by the actors. Figure 2 illustrates that the conflict was not dominated by a single concept. Nevertheless two frames stick out because they have been used significantly more often than others: "Competitiveness of SMEs" and "Innovation and Transfer of Knowledge". The opponents (e.g., software developers, SMEs, and some MEPs) claimed that the directive would endanger European SMEs, who lacked the knowledge and resources to use the patent system to their advantage, and supporters (large firms, European and national business associations, and again some MEPs) argued that SMEs would profit from the directive, as patented "computer implemented inventions" would attract venture capital. The second-most frequently used frame, innovation and transfer of knowledge, was usually combined by the opponents with the SME frame, arguing that SMEs are the cornerstone of innovation in Europe, and that by putting SMEs at a disadvantage, software patents would have a negative impact on European innovation. The other side generally followed the conventional wisdom of the economic and legal mainstream, which regarded strong intellectual property protection and especially patent protection as necessary for the protection of investments in innovation. According to this argument, not being able to file patents for computer-implemented inventions would keep large corporations from investing in Europe, which would negatively affect not only individual firms, but the whole European economy, resulting in the loss of many jobs. Thus, the competitiveness of SMEs and innovation frames were clarified and invigorated by both camps, though they were interpreted differently. The only relevant frame that was used exclusively by one side was the open access/open source frame. It was relevant to some degree in the internal discussions among opponent organizations, but in the public discourse it played only a minimal role.

It is important to note that the most often-used frames were contested. No side was able to claim a monopoly over these frames. Such a structure is typical of a political conflict in which both sides take up the arguments of each other. The political claims analysis also reveals to some extent how this is done: in the argumentation, frames were bundled with other frames that could not be appropriated as easily by the political opponent in an attempt to pull the core frames to the actor's respective camps. Figure 2 suggests that the opponents were more successful in this respect, since even the innovation frame, which was the core frame of the Commission's original argumentation, ended up with a value below zero, which means it was more often used in arguments against than for software patents. 


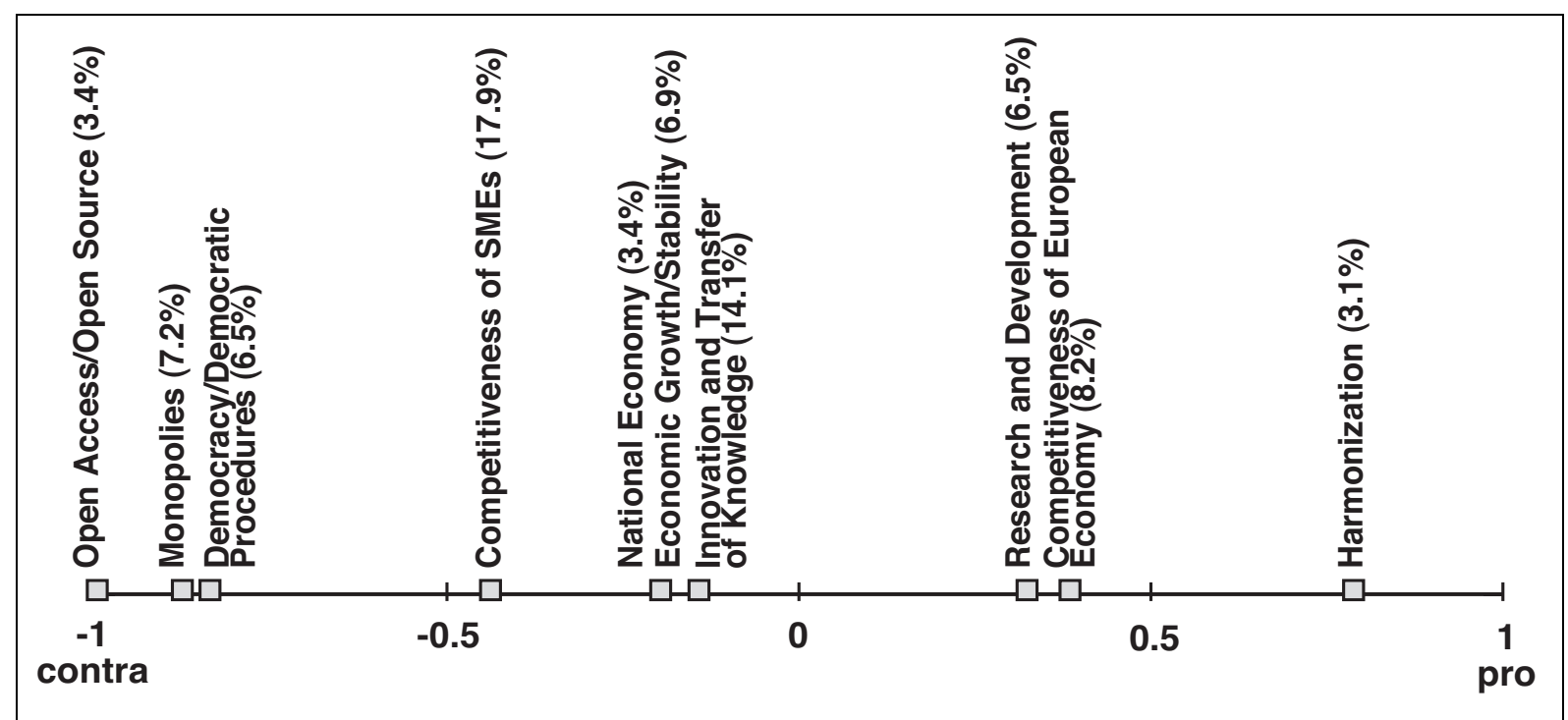

Figure 2: Mean frame positions

Note: Positions in this chart represent the mean position of the frames. The research and development frame, for example, was used six times in a claim against the directive, twelve times in support and one time in a neutral or ambivalent way, resulting in an overall score of $((-1 \cdot 6)+(1 \cdot 12)) / 19=0.32$.

The political claims analysis of the software patents conflict shows that the oppositional strategy is a good example of a successful re-framing strategy. Rather than concentrating their efforts on constructing a consistent counter-frame, the opponents successfully shifted the original frames used by the Commission, effectively turning them on their head. To do this, the opponents reaffirmed the necessity of innovation and a competitive European economy, but claimed that the principal agents of innovation in the European IT sector were SMEs and that only a directive that effectively prevented software patenting would safeguard innovation. Instead of attempting to establish a hegemonic counter frame, the opponents knit together various frames, a strategy that Haunss and Kohlmorgen have called "frame bundling" (Haunss \& Kohlmorgen 2009, p. 124). In addition, the opponents were able to construct a master frame according to which innovation depended on the competitiveness of SMEs, which could in turn only be secured without software patents. This provided a unified collective action perspective and allowed the opponents to mobilize a diverse constituency. Along with the democracy frame, it resonated in the broader SME sector, and, more importantly, with many MEPs, who finally stopped the directive - against the conventional wisdom of the EU interest-group literature that would have seen the much more resourceful and much better connected business associations and large software firms in a clear advantage.

Political claims analysis can thus be employed to analyze the empirical usage of frames by actors and, in this particular case, the successful mobilization of opponents of software patents. However, the analysis leaves us with substantial uncertainty about the details of the political discourse, particularly over time. Are there really two distinct coalitions, as suggested by the somewhat noisy one-dimensional depictions? If so, are they stable over time, as sug- 
gested by the Advocacy Coalition Framework or the concept of discourse coalitions? Does reframing, as discovered in a hermeneutic way, really take place, or are the actor coalitions mutually exclusive in their choice of frames? Using the same data that was used for the political claims analysis, we will demonstrate in the next section which additional insights can be gained by applying the relational perspective of discourse network analysis to the conflict.

\section{Discourse network analysis and its application to the software patents conflict}

In the following paragraphs, we will describe a complementary methodology using a similar approach to data collection: discourse network analysis is a combination of category-based content analysis and social network analysis. We will subsequently show how the relational information embedded in PCA data can be analyzed within the framework of discourse network analysis.

As for the measurement unit, discourse network analysis takes a similar approach as political claims analysis: statements of actors are the primary concern of data encoding. The latter takes place inside the text data instead of using a separate spreadsheet. This helps to review statements and their context later on and to do multi-pass encoding. The discourse network model has been implemented in a free-to-use software called Discourse Network Analyzer (DNA). ${ }^{2}$ It serves two purposes: assigning actor and category tags to text data, and extracting social networks from these structured data.

\section{Affiliation networks}

Figure 3 shows an illustration of the basic descriptive network model: there is a set of actors, $A=\left\{a_{1}, a_{2} \ldots a_{m}\right\}$, and a set of concepts, $C=\left\{c_{1}, c_{2} \ldots c_{n}\right\}$, which correspond to frames in the language of political claims analysis. An actor can either agree or disagree with a concept. Thus, there are two relations between actors and concepts, one for agreement and one for disagreement: $R=\left\{\begin{array}{lllll}r_{l}, & r_{2} & \ldots & r_{l}\end{array}\right\}$ with $l=2$. There is also a set of discrete time points $T=\left\{t_{1}, t_{2} \ldots t_{k}\right\}$ because the discourse network can be repeatedly observed.

The most basic form is a bipartite graph of actors referring to concepts either in a positive or in a negative way at a certain time point. The bipartite graph is called affiliation network. It is captured by the following equation:

$$
G_{r, t}^{a f f}=\left(A, C, E_{r, t}^{a f f}\right) \quad \text { with }\left\{a, a^{\prime}\right\} \notin E_{r, t}^{a f f} \wedge\left\{c, c^{\prime}\right\} \notin E_{r, t}^{a f f}
$$

In this equation, $a^{\prime}$ denotes an actor who is not identical with actor $a$, and $c^{\prime}$ denotes a concept that is not identical with concept $c . \quad E_{r, t}^{a f f}$ refers to the set of edges in the affiliation graph $G^{\text {aff }}$ at time $t$ and for relation $r$.

The affiliation network $G^{\text {aff }}$ corresponds to the solid lines between actors and concepts in the illustration. The dashed lines among the actors and among the concepts depict the two derived adjacency networks in which actors are connected who refer to the same concepts and in

\footnotetext{
2 The program can be downloaded from http://www.philipleifeld.de.
} 
which concepts are connected if they are used by the same actor (see below for details). Applied to empirical data, an actor is connected to a concept in the affiliation network if (s)he makes a claim/statement in the media. ${ }^{3}$

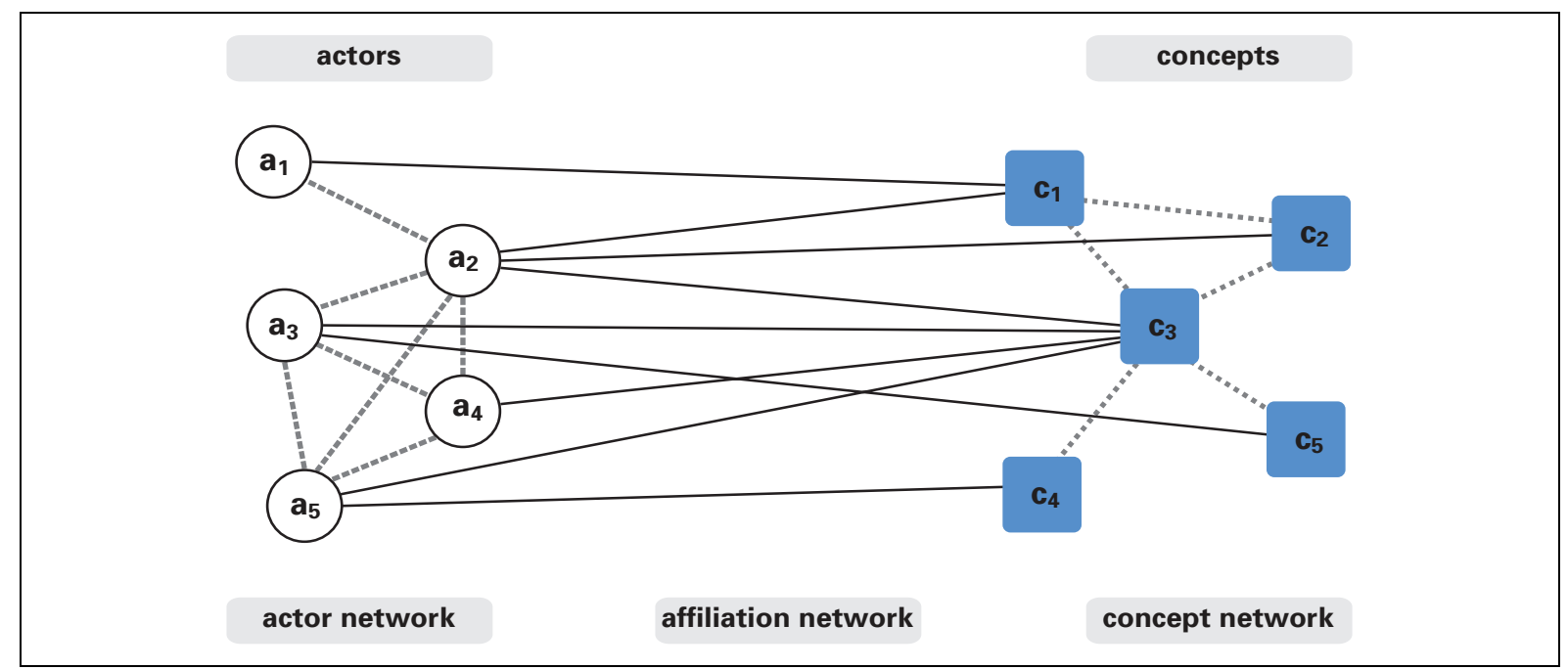

Figure 3: Illustration of the basic discourse network model

The concepts are in fact abstract categories under which certain claims can be subsumed. The categorization works like category-based, computer-assisted, qualitative data analysis, but the coder additionally specifies the actor to whom the statement can be attributed. The affiliation network can simultaneously show actors and concepts as well as their interrelations, which goes well beyond most existing measurement approaches to political discourse. Moreover, the data can be subdivided into several time slices in order to obtain repeated measurements of the discourse. Please note that there are two separate affiliation networks, one for the agreement and one for the disagreement relation. They can be easily combined in a multiplex network.

This is precisely what we have done when constructing the affiliation network of the software patents conflict depicted in figure 4. The visualization shows only the critical phase of the conflict, namely the last of the four waves described in the previous section, including all statements between February 2004 and July 2005. The graph can shed more light on the question which frames are contentious and which ones are "owned" by single coalitions.

As for the interpretation, opponents of software patents govern a number of frames almost exclusively. Among them are the endangered competitiveness of small and medium enterprises in the presence of software patents, the view that software patents might lead to undesirable monopolies, and complaints about undemocratic behavior of the Commission and the Council. The innovation and transfer of knowledge frame is used by both coalitions, but the net-

3 Possible data sources are newspaper articles, position papers, interview data and press releases. Depending on the data source, there may be different kinds of validity issues, which have already been reported elsewhere (e.g., Franzosi 1987). 
work analysis shows that a large number of oppositional actors refers to it whereas on the proponents' side mainly EICTA uses it over and over again.

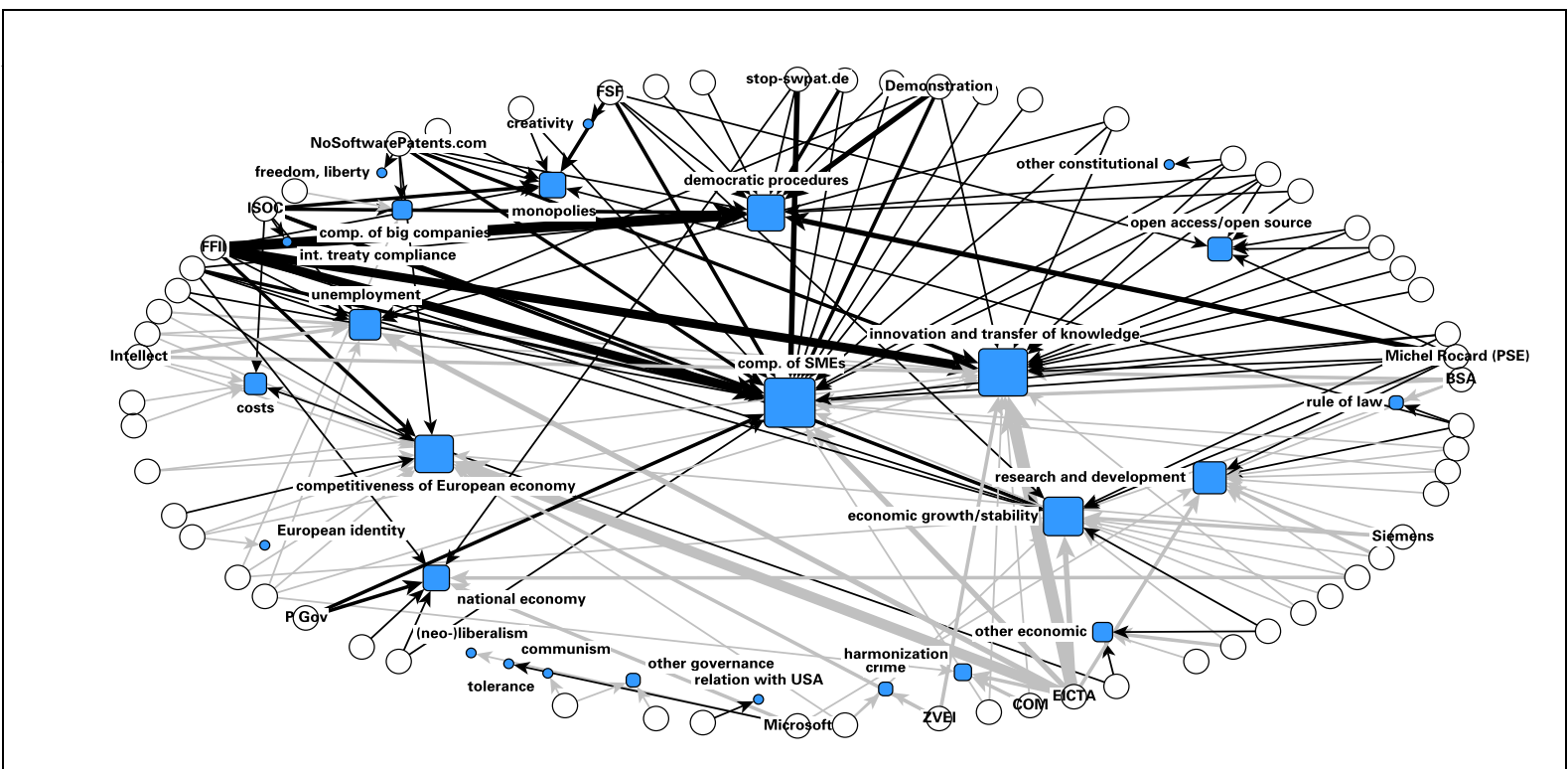

Figure 4: Affiliation network

Note: Gray edges are positive citations of frames (in favor of software patents), black lines are negative citations, thickness of the arcs represents the number of reported claims, size of the square nodes the indegree, i.e., how often this frame was referred to. Layout: Centrality layout (Brandes et al. 1999)

Proponents emphasize that software patents would promote European relations with the United States, that software patents would strengthen private research and development expenditures, that they would be needed for further European harmonization, and that stealing other people's ideas is a criminal act. Thus, the most contested points of view between the two coalitions refer to the economic sphere: economic growth and stability, and competitiveness of the European economy are cited by both camps in rather different ways. The fact that proponents of the directive fail to monopolize economic arguments, rely on value-laden frames, and do not manage to capture the core "competitiveness of SMEs" and "innovation and transfer of knowledge" frames may explain their defeat. In this final and most important stage of the discourse, opponents of software patents successfully re-frame some economic arguments and, moreover, gain possession of some of these arguments completely.

Beyond being able to identify the core frames, the affiliation network also reveals how other frames have failed to gain general traction and have been used only by selected actors. The competitiveness of national economies was obviously not the best frame for an EU-wide conflict, and remained confined mostly to national actors. Harmonization, the credo of the Commission, did not become popular either, nor did the open access/open source frame of the free software community. 


\section{Congruence networks}

This one-shot description becomes more interesting if several time slices are measured, and if changes in the affiliation of critical actors to certain solution concepts can be observed. However, tracking changes in affiliation networks can become a tedious task, and it is quite difficult to establish whether two actors actually exhibit high or low degrees of belief overlap, given this highly complex graphical representation of the discourse. One might not only be interested in how actors relate to concepts, but also in how far discourse coalitions emerge from this structure. The basic idea is that the more solution concepts two actors agree (or both disagree) on, the more similar they are in terms of common beliefs in the discourse, and the more likely they will belong to the same discourse or advocacy coalition. Thus, it is straightforward to move from a bipartite affiliation graph to an adjacency graph where actors are connected to other actors and where the edge weight between these actors represents the number of common concepts. The overall topology of the resulting congruence network can be used as a map of the discourse where clusters of actors represent discourse coalitions. The congruence network provides an intuitive way of conceptualizing and measuring advocacy or discourse coalitions (or other actor-centered discourse constructs, depending on the type of concepts used for categorization).

If the bipartite graph is a representation of a rectangular matrix $\quad X_{m \times n}$ where actors occupy the row labels and concepts the column labels, and where only the agreement relation or only the disagreement relation is shown, the congruence network can be obtained by computing $X X^{T}$, which yields a square actor $\mathrm{x}$ actor matrix with the number of shared concepts as the cell entries. Both relations can then simply be added in order to combine positive and negative citations of concepts in a single network. In graph-theoretical notation, the weighted congruence network is captured by the following equation:

$$
G_{t}^{a}=\left(A, w_{t}\right) \quad \text { with } \quad w_{t}\left(a, a^{\prime}\right)=\sum_{r=1}^{l}\left|E_{r, t}^{a f f}(a, C) \cap E_{r, t}^{a f f}\left(a^{\prime}, C\right)\right|
$$

In this congruence network, two actors are connected if they share a concept both in a positive or both in a negative way. The link between the actors is stronger the more concepts they share. The edge weight can therefore be interpreted as a measure of similarity between two actors in the discourse. In the illustration in figure 3 , the congruence network is represented by the dashed lines between the actors on the left. For example, actor 1 and actor 2 are connected because they both refer to concept 1 .

As is the case with actors, we can also construct a concept network based on the affiliations. In this co-occurrence network, two concepts are connected if they are used by the same actor, and the edge weight between two concepts equals the number of actors referring to both concepts:

$$
G_{t}^{c}=\left(C, w_{t}\right) \quad \text { with } \quad w_{t}\left(c, c^{\prime}\right)=\sum_{r=1}^{l}\left|E_{r, t}^{a f f}(c) \cap E_{r, t}^{a f f}\left(c^{\prime}\right)\right|
$$

The concept network is illustrated in the right part of figure 3. For instance, concept 1 and concept 3 are connected because they are both cited by actor 2 . The edge weight can be inter- 
preted as a measure of similarity between two concepts in the discourse. A cluster of concepts indicates that the member concepts of this cluster most likely belong to the same argument or ideology.

Figure 5 applies the idea of an actor-based congruence network to the software patent conflict. It was a polarized political conflict in which two competing coalitions existed. The PCA data indicate that very few claims are neutral, while most of them are either clearly for or against software patents. To some extent, this polarization is already visible in figure 1 , but the aggregation of individual actors into actor groups or categories somewhat obscures the real polarization of the conflict. However, if we employ discourse network analysis, there is no need to aggregate the actors.

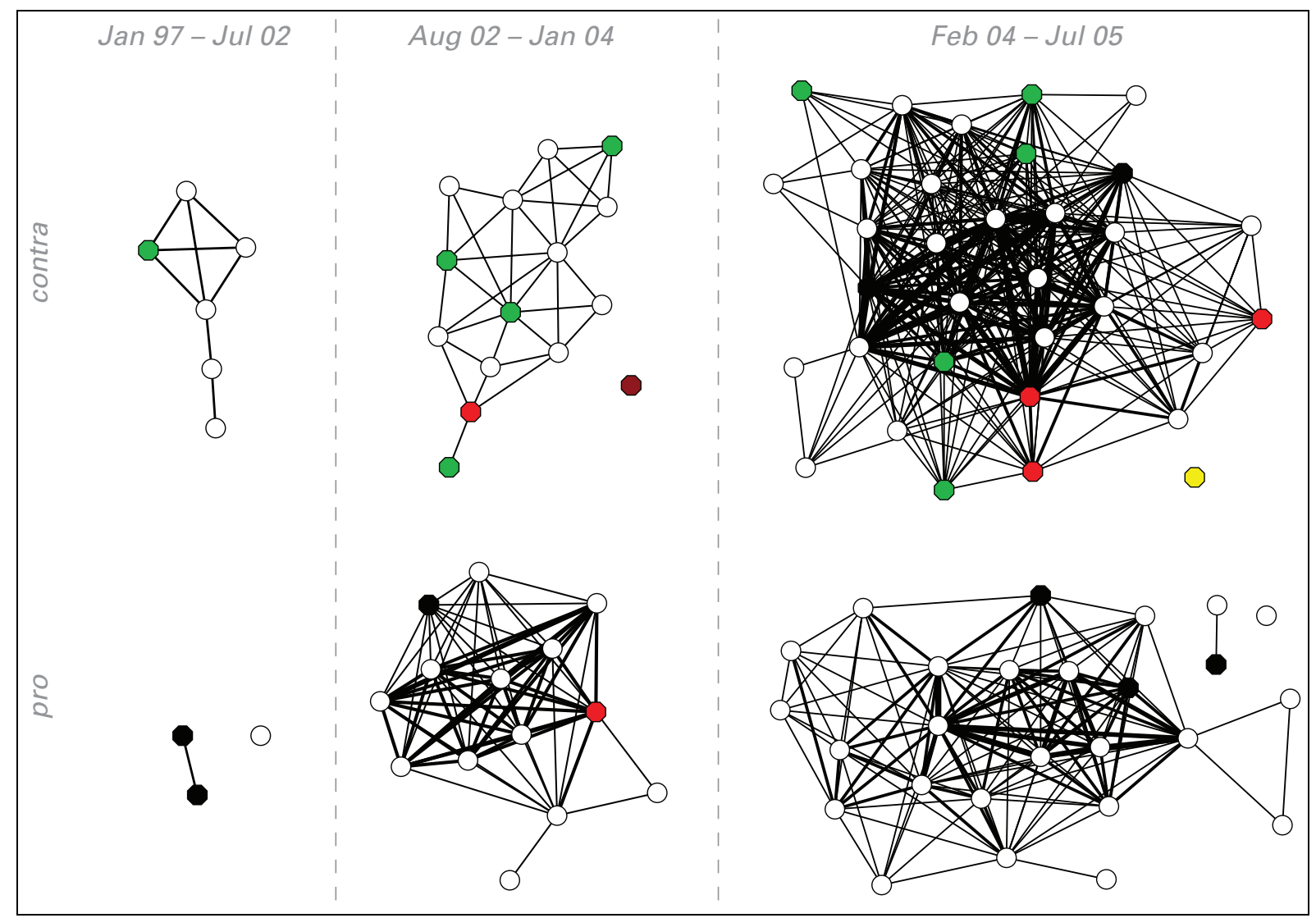

Figure 5: Congruence networks for three time periods: Jan 97 - Jul 02, Aug 02 - Jan 04, Feb $04-J u l 05$, from left to right

Note: Circles represent organizations while octagons are Members of the European Parliament (Greens/EFA green, PSE red, EPP-ED black, and GUE/NGL dark red). The pro-SWP coalition for each time period is in the lower half, the anti-SWP coalition in the upper half of the picture. Line width reflects the number of different frames two actors agree on. Actor labels have been omitted in order to improve legibility.

Figure 5 shows visualizations of the congruence network in the three periods presented in the political claims analysis of the software patents conflict. ${ }^{4}$ The first wave of the discourse from January 1997 to July 2002 consists of the European Commission (the blue vertex) and two

4 Due to the low number of claims in the first and the second period, we have combined them. 
French Members of the European Parliament (MEP) who belong to the European People's Party (EPP-ED). The anti-SWP coalition consists of a Green MEP as well as several other actors. All actors except for the European Commission are based in France. The first wave of the discourse obviously takes place in the French press only. The remaining two waves are mainly composed of EU-level actors with some exceptions from various European countries. In all waves, there is absolutely no overlap between the coalitions in terms of statements, while agreement within coalitions is substantial.

Let us take a look at Members of the European Parliament. If MEPs are aggregated at the level of political groups and over time, the two largest groups PSE and EPP-ED connect the two coalitions (cf. figure 6). Once broken down to the individual level and different time periods as in figure 5, however, the apparent broker role of the two biggest political groups disappears. Rather than mediating between the coalitions by taking up frames from both camps, PSE and EPP-ED are deeply divided between the two camps. Not a single MEP moves from one coalition to the other over time or adopts positions from both coalitions. This solves the puzzle which the political claims analysis in the previous section has revealed: the moderate position of the MEPs on the one-dimensional scale of figure 1 disappears and turns into extreme positions if MEPs are treated individually. The fact that the MEPs, although appearing rather moderate, tend towards the anti-SWP position on average can be attributed to the fact that a number of Green MEPs argues consistently over all time periods against software patents.

Another interesting finding from the congruence networks is the differential internal coherence of the coalitions: in the first two waves, we can observe that the anti-SWP coalition is not very clustered or dense (global weighted clustering coefficient: 0.75 and 0.56 , respectively; density: 0.32 and 0.36 ) while the pro-SWP subgraph - as a result of a common statement by most of its members - is almost completely connected in the second wave (clustering: 1.51; density: 0.77). In the third time period, the pattern is reversed: the anti-SWP coalition develops a rather consistent line of reasoning (clustering: 1.33; density: 0.77 ) while the coherence of the pro-SWP coalition is slightly diminished (clustering: 1.28; density: 0.55). The increased internal coherence of the opponents of software patents could be an explanation of their success in forestalling the software patents directive: the more coherent a coalition appears in the public sphere, the more able it is to convince key decision-makers and voters. Future research may show whether this hypothesis withstands comparative empirical tests.

\section{Conflict networks}

So far, co-occurrence networks of actors or concepts have been representations of similarity between actors or between concepts. However, there is another piece of information hidden in the original data: conflictual relations, or dissimilarity between vertices. For example, one actor makes a claim in a positive way while another actor makes the same claim in a negative 
way - in other words, one actor rejects the claim of the other actor. Conflict ties can be expected to be prevalent between the clusters of a congruence network, but not within clusters.

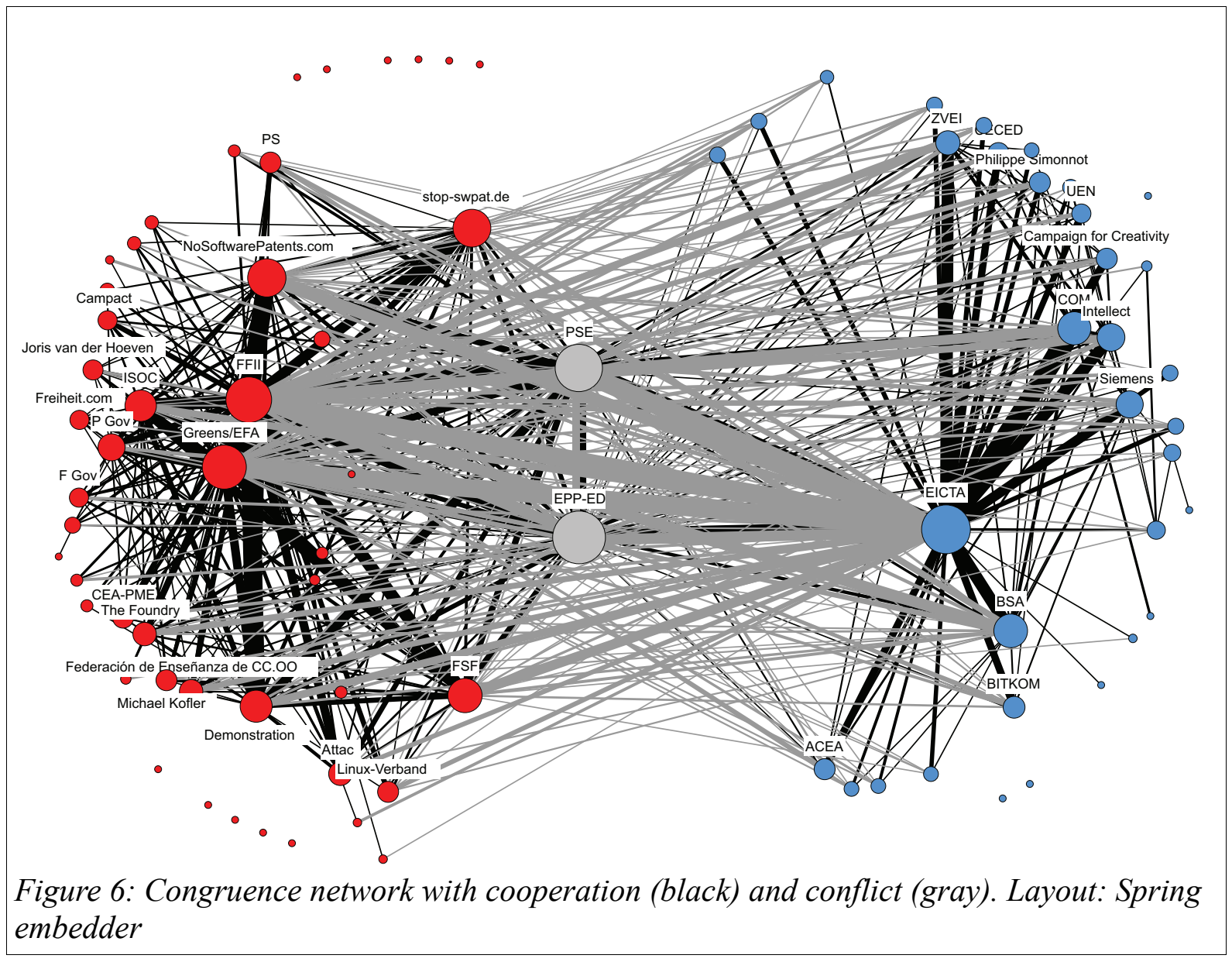

Figure 6 presents a multiplex view of the actor network over all time periods, with black edges representing congruence and gray lines conflict ties, i.e., direct contradictions between actors on the same frame. As expected, the congruence relation exhibits strong bipolarity between the coalitions. The more interesting question, however, is whether the camps simply occupy different, non-overlapping topics or whether they actually refer to the same contested frames and try to re-frame them according to their policy goals. The gray edges strongly suggest the latter. Conflict ties are in fact rare within congruence coalitions, but very prevalent between them. This can be confirmed statistically by considering the QAP correlation of -0.67 between congruence and conflict. The more frame congruence between two actors, the less likely are conflict ties. The result corroborates the intuition that frame amplification and reframing are important strategies in the public discourse, as set out in the political claims analysis in the previous section and as suggested by the initial analysis of the affiliation network. 


\section{Dynamic discourse networks}

As pointed out in the description of figure 5, political discourse is essentially a dynamic rather than a stable phenomenon. Discursive interactions are conditional on past interactions. One way to measure change over time is to subdivide the whole discourse into several time slices. We have done this in the analysis of the four waves of the software patent conflict. Beyond simply comparing static pictures, it is possible to use dynamic network visualization tools in order to visualize the changing roles of actors in an animation.

This is basically a discretization of time, which is actually continuous. However, by using discrete time steps, one may lose some information. Generating a continuous-time animation would be desirable. The above-mentioned software Discourse Network Analyzer offers several more nuanced ways to create dynamic discourse networks or to aggregate dynamic data into static representations. The description of these longitudinal algorithms, however, is beyond the scope of this article (see Leifeld 2010a; Leifeld 2010b for details).

\section{Advantages of discourse network analysis}

Political claims analysis and discourse network analysis share the insight that statements should be the primary unit of measurement and analysis, and that actors and concepts should be analyzed simultaneously. But what are the advantages of discourse network analysis over political claims analysis?

Firstly, political claims analysis assumes that a discourse surrounding one issue is one-dimensional. Actors and frames are marked on a range from -1 to +1 , designating opposition or support. This is also true of other text analysis approaches like the Wordscore project (Laver et al. 2003). Discourse network analysis conceptualizes political discourse as multidimensional, and one of the key insights it can generate is the number of cleavage lines that are actually empirically present in the discourse. Depending on the concepts used to code the data and the scope of the actors, it becomes possible to identify sub-topics and sub-coalitions in a policy subsystem. Political reality is complex, and discourse network analysis is a suitable tool to reduce this complexity to a degree that is interpretable by the researcher. A visualization of a discourse network immediately reveals how each single actor or concept is embedded in the discourse. At the same time, it is possible to assess the overall topography of the discourse and identify cleavage lines and roles of actor types. Many studies provide only anecdotal evidence for the existence of adversarial coalitions and changes in their composition. Apart from using visualizations directly as explanations (Brandes et al. 2006), network-analytic methods like blockmodeling or centrality (Wasserman \& Faust 1994) can be employed to measure network properties in a more reliable and valid way.

Secondly, discourse network analysis allows to distinguish neutral concepts from highly contentious concepts which are only neutral on average. In political claims analysis, both kinds of frames are placed in the middle of the one-dimensional scale: positive statements receive a 
score of +1 and negative statements a score of -1 . Positive and negative instances of the same frame are summed up, and the balance is taken as a measure of the pro or contra affiliation of a concept. It does not make a difference if a concept is ten times neutral, or if it is cited five times in a positive way and five times in a negative way. In discourse network analysis, neutral statements do not exist. If a concept is highly disputed, this is visible in the affiliation network because actors from one camp will cite the concept in a positive way, while actors from the other camp will cite it in a negative way. If the pattern is less clear-cut between the camps, the concept is more neutral.

Thirdly, discourse network analysis allows to track changes in the discourse over time. Political claims analysis offers time series graphs of discourse activity and of the number of positive and negative citations at each time step. Discourse network analysis allows to observe if an actor leaves a coalition and joins another coalition over time, or if a formerly united discourse is polarized and develops two or more distinct clusters of concepts over time. This meets the demand of policy network scholars who have called for dynamic policy network analyses for a long time (McAdam 2003). The collection of network data is usually costly, so there have been only few longitudinal network studies. Discourse network analysis allows to accomplish this task, albeit for the sake of changing research questions away from (material) coordination as in the policy networks approach towards (latent) preference similarity. Dynamic discourse network analysis also meets the demand of scholars interested in longitudinal changes in policy ideas and learning (Hall 1993, p. 290ff.).

Fourthly, discourse network analysis can be nicely combined with other policy network approaches. Methods such as QAP regression (Krackhardt 1988) or exponential random graph models (Robins et al. 2007) provide means to treat discursive ties as covariates of other network relations.

Fifthly, the approach presented here can be conceived of as a lens through which a discourse can be observed. Therefore it is not only applicable to empirical data. Discourse network analysis could be employed to understand the results of computational models of discourse or to theorize about discourse-related behavior of actors.

Finally, discourse network analysis is flexible regarding the type of concepts used in the analysis. Discourse network analysis is not confined to the analysis of frames. It can be applied to the actors' choice of solution concepts (Hall 1993), linguistic peculiarities or symbols (Wodak \& Meyer 2009), beliefs (Sabatier \& Weible 2007) or interpretive frames (Hajer 1995), as in our analysis of the software patents conflict.

\section{Conclusion}

In this article, we have proposed a new methodology for the analysis of political discourse which is complementary to existing approaches such as political claims analysis. Moreover, 
we have applied this approach to the European conflict about software patents. As for the software patent case study, the analysis in the preceding sections has produced a number of interesting findings and hypotheses:

- The constellation shows all elements of a highly politicized conflict. The actors are split into two very distinct discourse coalitions which do not share a single conviction. However, topical overlap between the coalitions is large, and conflicts between the coalitions (but not within coalitions) are prevalent.

- The European parties do not act as brokers between the discourse coalitions. Individual MEPs rather stick to one or the other coalition. This runs counter to models of policy-making where parties take intermediary positions (e.g., the role of brokers as hypothesized in the Advocacy Coalition Framework, or the moderating role of parties in pressure pluralist or neo-corporatist systems).

- Over time, the internal coherence of the anti-SWP coalition increases while the internal coherence of the pro-SWP coalition decreases. We interpret this as a learning process in which the emerging oppositional coalition first has to develop a shared collective action frame. Once this unifying frame has been established, it has certainly improved the chances of the anti-SWP coalition to impede the SWP directive.

- The anti-SWP coalition is able to reclaim important economic frames in the last stage of the political discourse while the pro-SWP coalition is left with value-laden arguments and some highly contested economic frames, which may have further contributed to the defeat of the pro-SWP coalition.

These substantial findings demonstrate that discourse network analysis is capable of producing insights which were previously unobservable when relying on conventional approaches. Particularly, the discourse network framework allows to

- track the evolution of a discourse over time,

- observe the overall topography of the discourse on the actor level, concept level or a combined display, thus providing the missing link between actors and concepts,

- measure discourses in a multidimensional way, rather than imposing a one-dimensional, reductionist constraint on the data, and

- distinguish neutral from contentious concepts, something that political claims analysis is only able to accomplish in a qualitative way.

However, there are potential limitations of this approach that researchers should keep in mind: archival data like newspaper articles, position papers or parliamentary protocols answer different research questions than interviews or participant observation. While the former are tailored for policy learning and discourse theories like the Advocacy Coalition Framework, the latter may be able to explain policy change by reverting to power positions, bargaining or institutions. Integration of these factors into a discourse network analysis is only possible on a qualitative basis at the present time. A policy network analysis of the same conflict (Haunss \& 
Kohlmorgen 2010), which uses more diverse data sources (interviews, newspaper articles, documents, web pages), shows that the discourse network generated from newspaper articles only partially represents the actors involved in the conflict. Public discourse represented in newspapers is skewed toward certain actors. Particularly MEPs are highly visible in the media, which probably overstates their ability to shape the political conflict. Conversely, many smaller organizations, NGOs and individual actors are underrepresented in the news if compared with the conflict network (Haunss \& Kohlmorgen 2010). Consequently, the analysis of discourse networks should be combined with conventional methods. It is well equipped for this task because its data structure is largely compatible with policy network analysis.

\section{References}

Adam, S. \& Kriesi, H., 2007. The Network Approach. In P. A. Sabatier, ed. Theories of the Policy Process. Boulder, CO: Westview Press, pp. 129-154.

Baumgartner, F.R. \& Jones, B.D., 1991. Agenda Dynamics and Policy Subsystems. The Journal of Politics, 53(4), 1044-1074.

Beyeler, M. \& Kriesi, H., 2005. Transnational Protest and The Public Sphere. Mobilization, 10(1), 95-109.

Beyers, J., 2004. Voice and Access. Political Practices of European Interest Associations. European Union Politics, 5(2), 211-240.

Bouwen, P., 2004. Exchanging Access Goods for Access: A Comparative Study of Business Lobbying in the European Union Institutions. European Journal of Political Research, 43, 337-369.

Brandes, U. \& Corman, S.R., 2003. Visual Unrolling of Network Evolution and the Analysis of Dynamic Discourse. Information Visualization, 2(1), 40-50.

Brandes, U., Kenis, P. \& Raab, J., 2006. Explanation through Network Visualization. Methodology, 2(1), 16-23.

Brandes, U. et al., 1999. Explorations into the Visualization of Policy Networks. Journal of Theoretical Politics, 11(1), 75-106.

Carley, K. et al., 2009. AutoMap User's Guide 2009. Technical Report CMU-ISR-09-114. Available at: http://www.casos.cs.cmu.edu/publications/papers/CMU-ISR-09-114.pdf [Accessed May 4, 2010].

COM, 1997. Promoting innovation through patents. Green Paper on the Community patent and the patent system in Europe, Brussels: Commission of the European Communities.

Dolezal, M., Helbling, M. \& Hutter, S., 2010. Debates over Islam in Austria, Germany, and Switzerland: Between Ethnic Citizenship, State-Church Relations, and Right-Wing Populism. West European Politics, 33(2).

Franzosi, R., 1987. The Press as a Source of Socio-Historical Data: Issues in the Methodology of Data Collection from Newspapers. Historical Methods, 20(1), 5-16.

Giugni, M. \& Passy, F., 2004. Migrant Mobilization between Political Institutions and Citizenship Regimes: A Comparison of France and Switzerland. European Journal of Political Research, 43(1), 51-82.

Haas, P.M., 1992. Introduction: Epistemic Communities and International Policy Coordination. International Organization, 46(1), 1-35.

Hajer, M.A., 1995. The Politics of Environmental Discourse: Ecological Modernization and the Policy Process, Oxford: Oxford University Press. 
Hall, P.A., 1993. Policy Paradigms, Social Learning, and the State: the Case of Economic Policymaking in Britain. Comparative politics, 25(3), 275-296.

Haunss, S. \& Kohlmorgen, L., 2010. Conflicts About Intellectual Property Claims: The Role and Function of Collective Action Networks. Journal of European Public Policy, 17(2). Available at: http://ssrn.com/paper=1162209.

Haunss, S. \& Kohlmorgen, L., 2009. Lobbying or Politics? Political Claims-Making in IP Conflicts. In S. Haunss \& K. C. Shadlen, eds. The Politics of Intellectual Property. Cheltenham, Glos: Edward Elgar Publishing.

Haunss, S. \& Shadlen, K.C. eds., 2009. Politics of Intellectual Property. Contestation over the Ownership, Use, and Control of Knowledge and Information, Cheltenham, Glos: Edward Elgar Publishing.

Hurrelmann, A. et al., 2009. Why the democratic nation-state is still legitimate: A study of media discourses. European Journal of Political Research, 48(4), 483-515.

Hurrelmann, A., Schneider, S. \& Steffek, J. eds., 2007. Legitimacy in an Age of Global Politics, Basingstoke: Palgrave Macmillan.

Janning, F. et al., 2009. Diskursnetzwerkanalyse. Überlegungen zur Theoriebildung und Methodik. In V. Schneider et al., eds. Politiknetzwerke. Modelle, Anwendungen und Visualisierungen. Wiesbaden: VS Verlag, pp. 59-92.

Kenis, P. \& Schneider, V., 1991. Policy Networks and Policy Analysis. Scrutinizing a New Analytical Toolbox. In B. Marin \& R. Mayntz, eds. Policy Networks. Empirical Evidence and Theoretical Considerations. Frankfurt am Main: Campus, pp. 25-59.

Kohler-Koch, B., 1997. Organized Interests in the EC and the European Parliament. European Integration Online Papers, 1(9). Available at: http://ssrn.com/abstract=302669.

Koopmans, R. \& Statham, P., 2001. How national citizenship shapes transnationalism. A comparative analysis of migrant claims-making in Germany, Great Britain and the Netherlands. Revue Européenne des Migrations Internationales, 17(2), 63-100.

Koopmans, R. \& Statham, P., 1999. Political Claims Analysis: Integrating Protest Event and Political Discourse Approaches. Mobilization: An International Quarterly, 4(2), 203221.

Krackhardt, D., 1988. Predicting with Networks: Nonparametric Multiple Regression Analysis of Dyadic Data. Social Networks, 10(4), 359-381.

Lang, A. \& Leifeld, P., 2009. Die Netzwerkanalyse in der Policy-Forschung. Eine theoretische und methodische Bestandsaufnahme. In F. Janning \& K. Toens, eds. Die Zukunft der Policy-Forschung. Theorien, Methoden, Anwendungen. Wiesbaden: VS Verlag, pp. 223-241.

Laver, M., Benoît, K. \& Garry, J., 2003. Extracting Policy Positions from Political Texts Using Words as Data. American Political Science Review, 97(2), 311-331.

Leifeld, P., 2009. Die Untersuchung von Diskursnetzwerken mit dem Discourse Network Analyzer (DNA). In V. Schneider et al., eds. Politiknetzwerke. Modelle, Anwendungen und Visualisierungen. Wiesbaden: VS Verlag, pp. 301-404.

Leifeld, P., 2010a. Discourse Network Analyzer (DNA) Manual. Available at: http://www.philipleifeld.de/discourse-network-analyzer-dna/manual/.

Leifeld, P., 2010b. Political Discourse Networks - The Missing Link in the Study of PolicyOriented Discourse. In Paper presented at the workshop "Ideas, Policy Design and Policy Instruments: Casting the Missing Link", ECPR Joint Sessions, Münster, March 22-27, 2010. Available at: http://www.philipleifeld.de.

Lindekilde, L.E., 2008. Claims-Making of Danish Muslims during the Muhammad Caricatures Controversy: A Challenge to the Principles of the Secular Public Sphere?, Florence: Department of Political and Social Sciences, European University Institute. 
McAdam, D., 2003. Beyond Structural Analysis: Toward a More Dynamic Understanding of Social Movements. In M. Diani \& D. McAdam, eds. Social Movements and Networks. Oxford: Oxford Univ. Press, pp. 281-298.

Popping, R., 2003. Knowledge Graphs and Network Text Analysis. Social Science Information, 42(1), 91-106.

Robins, G. et al., 2007. An Introduction to Exponential Random Graph (p*) Models for Social Networks. Social Networks, 29(2), 173-191.

Sabatier, P.A. \& Weible, C.M., 2007. The Advocacy Coalition Framework. In P. A. Sabatier, ed. Theories of the Policy Process. Boulder, CO: Westview Press, pp. 189-220.

Snow, D.A. \& Benford, R.D., 1992. Master Frames and Cycles of Protest. In A. D. Morris \& C. M. Mueller, eds. Frontiers in social movement theory. New Haven, CT: Yale University, pp. 133-155.

Statham, P. \& Gray, E., 2005. The Public Sphere and Debates about Europe in Britain. Internalized and Conflict Driven? Innovation, 18(1), 61-81.

Steensland, B., 2008. Why do Policy Frames Change? Actor-Idea Coevolution in Debates Over Welfare Reform. Social Forces, 86(3), 1027-1054.

Wasserman, S. \& Faust, K., 1994. Social Network Analysis: Methods and Applications, Cambridge: Cambridge University Press.

Wodak, R. \& Meyer, M., 2009. Critical Discourse Analysis: History, Agenda, Theory and Methodology. In R. Wodak \& M. Meyer, eds. Methods for Critical Discourse Analysis. London: Sage, pp. 1-33. 